\title{
Defective Venous Beta-adrenergic Response in Borderline Hypertensive Subjects Is Corrected by a Low Sodium Diet
}

Ross D. Feldman

With the technical assistance of Christine Sinkey and Gladys Rios

Departments of Internal Medicine and Pharmacology, University of Iowa College of Medicine, Iowa City, Iowa 52242

\begin{abstract}
Hypertensive patients have reduced lymphocyte beta-adrenergic responsiveness which is corrected by a low sodium $(\mathrm{Na}$ diet. To determine if this represents a more generalized abnormality in beta adrenoceptor response, we studied beta adrenergic-mediated vasodilation in hand veins of borderline hypertensive subjects and controls. Subjects received a 5-d diet containing high $\mathrm{Na}$ /low potassium $(\mathrm{K})$, high $\mathrm{Na}$ /high $\mathrm{K}$, or low $\mathrm{Na} / \mathrm{high} \mathrm{K}$. Venous distension, as evaluated by a linear variable differential transformer, was measured in relation to infusion of phenylephrine followed by isoproterenol and nitroglycerin.
\end{abstract}

On both the high $\mathrm{Na}$ /high $\mathrm{K}$ and high $\mathrm{Na}$ /low $\mathrm{K}$ diets, hypertensive subjects had significantly decreased isoproterenol-mediated vasodilation (47\% decrease, $P<0.01$ and $36 \%$ decrease, $P<0.01$, respectively). On the low $\mathrm{Na} /$ high $\mathrm{K}$ diet, isoproterenol-mediated vasodilation in hypertensive subjects increased $41 \%(P<0.01)$ to a level not different from controls. Nitroglycerin-mediated vasodilation was not different in normotensive and hypertensive subjects, nor was it altered with $\mathrm{Na}$ intake. Phenylephrine-mediated vasoconstriction did not differ between normotensive and hypertensive groups. Venous beta-adrenergic response correlated with lymphocyte beta adrenoceptor density in normotensive $(r=0.53, P<0.005)$ but not hypertensive subjects. This study demonstrates that betaadrenergic responsiveness is selectively reduced in peripheral veins of borderline hypertensive subjects, and this is corrected by a low $\mathrm{Na}$ diet. In view of our previous findings of reduced lymphocyte beta-adrenergic responsiveness in borderline hypertension, these studies suggest a generalized defect of beta adrenoceptor responsiveness in human hypertension. Further, dietary $\mathrm{Na}$ may play an important role in regulating this abnormality. (J. Clin. Invest. 1990. 85:647-652.) alpha-adrenergic • beta-adrenergic $\bullet$ linear variable differential transformer $\cdot$ lymphocytes • vascular

\section{Introduction}

A defect in vasodilator function could be an important mechanism in the pathogenesis and/or maintenance of the hyperten-

This work was presented in part at the 61 st Annual Scientific Session of the American Heart Association and published in abstract form (1988. Circulation. 78:166. [Abstr.]).

Address correspondence to: Dr. R. D. Feldman, Dept. of Medicine, University of Western Ontario, 6-OF-11 University Hospital, P. O. Box 5339, London, Ontario, Canada N6A 5A5.

Received for publication 24 April 1989 and in revised form 8 September 1989.

\section{J. Clin. Invest.}

(C) The American Society for Clinical Investigation, Inc.

0021-9738/90/03/0647/06 \$2.00

Volume 85, March 1990, 647-652 sive state. Specifically, defective vasodilator function could contribute to both increased arterial resistance and reduced venous compliance. Vasodilator response to beta adrenoceptor agonists is reduced in several rat models of hypertension (1, 2). Reduced beta adrenergic-mediated vasodilation with normal or elevated alpha adrenergic-mediated vasoconstriction would be expected to lead to an imbalance in alpha-adrenergic/beta-adrenergic response. Under these conditions, sympathoadrenal stimulation would lead to a functional increase in arterial resistance and/or a decrease in venous compliance.

Despite a generalized finding of reduced beta-adrenergic responsiveness in rat models of hypertension, the evidence for reduced beta-adrenergic response in human hypertension has been less persuasive (reviewed in reference 1). Reduced isoproterenol-stimulated cardiac chronotropic response in hypertensive subjects has been reported by some but not all investigators (reviewed in reference 1). Further, it has been suggested that any alteration in isoproterenol-mediated heart rate response in hypertensive subjects is more likely to be an indirect mechanism, such as altered baroreflex sensitivity, than a direct effect (i.e., via a reduction in myocardial beta-adrenergic sensitivity) (3).

To determine whether a defect in the human beta adreno- $_{2}$ ceptor complex might be detected in hypertension, we previously studied beta adrenoceptors on lymphocytes. We found that beta ${ }_{2}$ adrenoceptor responsiveness (as assessed by isoproterenol-stimulated adenylyl cyclase activity) was decreased in lymphocytes from hypertensive subjects (4), and more recently demonstrated that this defect was corrected when hypertensive subjects were fed a low sodium chloride diet (5). However, the relevance of these findings to alterations in vascular beta adrenoceptor response remained unknown. The current studies were performed to assess whether venous beta-adrenergic response was reduced in human hypertension, and if so, whether this defect was correctable with dietary sodium chloride restriction.

Michel and colleagues have suggested that alterations in lymphocyte beta $_{2}$ adrenoceptor density might parallel alterations in cardiac beta (but not beta $_{1}$ ) adrenoceptor response $(6,7)$. Whether lymphocyte beta adrenoceptor density parallels vascular beta adrenergic-mediated response in man has not previously been addressed. Therefore, the present studies also were designed to determine whether lymphocyte beta adrenoceptor density correlated with vascular beta-adrenergic responsiveness.

To assess venous responsiveness we used the linear variable differential transformer (LVDT) ${ }^{1}$ technique to measure alterations in the distensibility of superficial hand veins with drug infusions. This specific technique for the assessment of the direct effects of drugs on venous tone was first described by

1. Abbreviations used in this paper: IPIN, [ ${ }^{125}$ I]iodopindolol; LVDT, linear variable differential transformer. 
Aellig $(8,9)$. The utility of LVDT as a sensitive and reproducible means of assessing peripheral vein adrenergic responsiveness was subsequently demonstrated by Alradi and Carruthers (10). LVDT techniques have been used to demonstrate that venous beta adrenoceptor responsiveness is reduced in the elderly (11), and that responsiveness to alpha-adrenergic agonists $(11,12)$ and nitroglycerin (13) are not changed. Further, this technique is minimally invasive, uses extremely small concentrations of drugs (avoiding systemic effects), and can be used repeatedly.

The data to be presented suggest that venous beta adrenoceptor responsiveness is selectively reduced in hypertensive subjects fed a high sodium chloride diet and is corrected when sodium chloride is restricted. Furthermore, we found that lymphocyte beta adrenoceptor density is correlated with vascular beta-adrenergic response in normotensive subjects but not in hypertensive subjects.

\section{Methods}

Subject protocol. Male normotensive and borderline hypertensive subjects between the ages of 20 and 31 yr were studied. Hypertensive subjects were otherwise healthy and had neither cardiovascular nor renal complications. They had not received any medications within $8 \mathrm{~d}$ of the study and none had previously received any antihypertensive drugs. The criteria for classifying subjects were identical to those used in previous studies (5). The borderline hypertensive subjects $(n=11)$ had diastolic pressures of $>90 \mathrm{mmHg}$ intermittently on at least $20 \%$ of daily morning blood pressure measurements taken in the sitting position during the study periods, or had diastolic pressures of $>90 \mathrm{mmHg}$ on at least $20 \%$ of continuously monitored ambulatory blood pressures taken over 12-24 h. The normotensive subjects $(n=11)$ had no diastolic blood pressures $>90 \mathrm{mmHg}$ on at least 12 occasions, and $<10 \%$ of continuously monitored diastolic blood pressures $>90 \mathrm{mmHg}$.

Subjects were studied in the University of Iowa Clinical Research Center on up to three occasions, $5 \mathrm{~d}$ after initiation of their diets. These consisted of a 400 meq sodium/100 meq potassium diet (in 8 normotensives and 8 hypertensives), a 400 meq sodium $/ 30$ meq potassium diet (in 11 normotensives and 10 hypertensives), or a 10 meq sodium/ 100 meq potassium diet (in 8 normotensives and 8 hypertensives). Calcium intake $(325 \mathrm{mg} / 1,000 \mathrm{kcal})$ was constant. The subjects were assigned to the diets in random order. On the morning of day 5 after overnight supine rest an indwelling catheter was inserted, and $20 \mathrm{~min}$ later a 100-ml blood sample was drawn. Blood was analyzed for lymphocyte beta adrenoceptor density as described below. To assess dietary compliance, a 24-h urine collection was performed during the last day of each study period and analyzed for sodium and potassium concentration with an ion-selective electrode (E2A Na/K electrode system; Beckman Instruments, Inc., Palo Alto, CA). Plasma renin activity was determined by radioimmunoassay (14).

Immediately after the blood sample was drawn venous responsiveness was studied as outlined below.

Assessment of venous responsiveness by LVDT. Venous adrenergic responsiveness assessed by LVDT was performed according to modifications of the methods of Alradi and Carruthers (10) and Pan et al. (11). The LVDT and Schaevitz modular LVDT signal conditioner used in these studies were manufactured by the Biomedical Engineering service, University of Western Ontario, London, Ontario, to the specifications previously described by Alradi and Carruthers (10). During the study the subject was kept supine with one arm resting on a padded support elevated at an angle $30^{\circ}$ from the horizontal. A 23 gauge needle was inserted in an appropriate dorsal hand vein and continuous infusion of $5 \%$ dextrose started at $0.12 \mathrm{ml} / \mathrm{min}$ with an infusion pump (Harvard Apparatus Co.? Inc., S. Natick, MA). All drugs were infused through this infusion needle. The LVDT apparatus was then placed over a dorsal hand vein with the central plunger of the

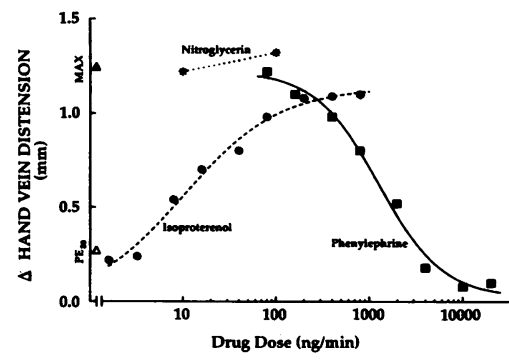

Figure 1. Assessment of vascular adrenergic responsiveness by LVDT. After assessment of baseline maximal distension $(M A X)$ increasing doses of phenylephrine (a) was infused until a maximal constrictor response is seen. After a washout period the dose of phenylephrine required for $80 \%$ of maximal constriction $\left(P E_{80}\right)$ was infused concurrently with increasing doses of isoproterenol to the maximal vasodilation response $(\bullet)$ followed by two doses of nitroglycerin (*). The figure represents the results of a study performed on a normotensive subject.

device resting on the apex of the vessel $1 \mathrm{~cm}$ from the tip of the infusion needle. To assess maximal distension, a pneumatic cuff on the ipsilateral arm was inflated to $50 \mathrm{mmHg}$, causing venous congestion and upward displacement of the plunger of the LVDT device. The difference in the position of the plunger between the resting position and full distension under baseline conditions was defined as maximal distension (100\%) (Fig. 1).

Assessment of alpha adrenergic-induced venoconstriction was determined by infusion of increasing doses of phenylephrine $(80-10,000$ $\mathrm{ng} / \mathrm{min}$ ). Each infusion lasted at least $5 \mathrm{~min}$. The pneumatic cuff was inflated for at least the final 2 min of each infusion, and the extent of venous distension was determined at each dose level upon release of the cuff. The concentration required for 50 and $80 \%$ of maximal phenylephrine-induced constriction $\left(\mathrm{ED}_{50}\right.$ and $\mathrm{ED}_{\mathbf{8 0}}$, respectively), as well as the extent of maximal phenylephrine-induced constriction (as a percentage of baseline distension), were determined using nonlinear curve-fitting methods (sigmoid plot subroutine, GraphPad program, ISI)

To determine isoproterenol- and nitroglycerin-induced vasodilation, vessels were first preconstricted to $\sim 80 \%$ of maximal phenylephrine-induced effect. The dose of phenylephrine used was individualized at each study session. Isoproterenol was then concurrently infused at concentrations from 1.6 to $1,000 \mathrm{ng} / \mathrm{min}$. The extent of distension at each dose level was determined (Fig. 1). Maximal isoproterenol-mediated venodilation, as well as $\mathrm{ED}_{50}$ for isoproterenol, were determined by analysis of the data with computerized curve-fitting as above. Finally, nitroglycerin-mediated responses were determined at doses of 10 and $100 \mathrm{ng} / \mathrm{min}$ (with concurrent phenylephrine infusion).

Lymphocyte isolation and permeabilization. Lymphocytes were isolated from EDTA anticoagulated blood according to the method of Boyum (15). Cells were washed and permeabilized for radioligand binding studies as recently described (16). Briefly, after separation on a Ficoll-Hypaque gradient, mononuclear cells were harvested as previously described, resuspended in Hanks' balanced salt solution (without $\mathrm{Ca}^{2+}, \mathrm{Mg}^{2+}$ ), centrifuged for $10 \mathrm{~min}$ at $400 \mathrm{~g}$, and resuspended in Hanks' balanced salt solution ( $\mathrm{pH} 7.4$ at $4^{\circ} \mathrm{C}$ ) with $33 \mathrm{mM}$ Hepes, 0.5 mM EDTA, and $2 \mathrm{mM}$ magnesium sulfate. Cells were permeabilized with digitonin (Sigma Chemical Co., St. Louis, MO) at a final concentration of $7.5 \mathrm{mg} / 100 \mathrm{ml}$. Cells were incubated for $15 \mathrm{~min}$ at $4^{\circ} \mathrm{C}$ washed at $400 \mathrm{~g}$ for $10 \mathrm{~min}$ at $4^{\circ} \mathrm{C}$, resuspended in Hanks' balanced salt solution, Hepes, EDTA, magnesium sulfate solution as above, washed again, and resuspended for radioligand binding studies at a concentration of $2-5 \times 10^{6}$ cells $/ \mathrm{ml}$.

Radioligand binding studies. Beta adrenoceptor binding studies were performed in permeabilized lymphocytes according to our previously described method with the use of [ ${ }^{125}$ I]iodopindolol (IPIN; 2,200 Ci/mmol; New England Nuclear, Boston, MA) (17). Eight concentrations of IPIN (10-100 pM) were used in each assay. Nonspecific binding was defined as that binding not blocked by propranolol (1 
Table I. Effect of Varying Sodium and Potassium Intake on Urinary Electrolytes, Plasma Catecholamines, and Mean Arterial Pressure

\begin{tabular}{|c|c|c|c|c|c|c|}
\hline & \multicolumn{3}{|c|}{ Normotensive } & \multicolumn{3}{|c|}{ Hypertensive } \\
\hline & Low Na/high $\mathrm{K}$ & High $\mathrm{Na} /$ low $\mathrm{K}$ & High Na/high K & Low $\mathrm{Na} /$ high $\mathrm{K}$ & High $\mathrm{Na} /$ low $\mathrm{K}$ & High Na/high $\mathrm{K}$ \\
\hline $\begin{array}{l}\text { Urinary sodium } \\
(m e q / d)\end{array}$ & $23 \pm 7$ & $346 \pm 27$ & $300 \pm 33$ & $20 \pm 4$ & $347 \pm 20$ & $357 \pm 28$ \\
\hline $\begin{array}{l}\text { Urinary potassium excretion } \\
\text { (meq/d) }\end{array}$ & $66 \pm 6$ & $33 \pm 3$ & $66 \pm 5$ & $69 \pm 11$ & $39 \pm 2$ & $71 \pm 4$ \\
\hline $\begin{array}{l}\text { Plasma renin activity } \\
(\mathrm{ng} / \mathrm{ml} \mathrm{per} h) \\
\text { Mean arterial pressure }\end{array}$ & $\begin{array}{l}7.1 \pm 1.3 \\
84 \pm 2\end{array}$ & $\begin{array}{l}0.6 \pm 0.2 \\
88 \pm 1\end{array}$ & $\begin{array}{l}0.9 \pm 0.2 \\
87 \pm 2\end{array}$ & $\begin{array}{l}8.3 \pm 0.9 \\
95 \pm 4\end{array}$ & $\begin{array}{c}0.8 \pm 0.2 \\
98 \pm 3^{*}\end{array}$ & $\begin{array}{l}1.3 \pm 0.2 \\
100 \pm 3^{*}\end{array}$ \\
\hline
\end{tabular}

${ }^{*} P<0.0167$ vs. normotensive controls.

$\mu \mathrm{M})$. Radioligand binding data were analyzed using a computerized curve-fitting program (Scatfit), and estimates were derived for beta adrenoceptor density $\left(B_{\max }\right)$ and affinity for IPIN.

Statistical analysis. All measures of potency (e.g., $\left.\mathrm{ED}_{50}\right)$ were expressed as geometric means $\pm \operatorname{SEM}(18,19)$. All other parameters were expressed as arithmetic means \pm SEM.

Differences in vascular response and beta adrenoceptor density between hypertensive and normotensive subjects, with the three diets, were compared using an unpaired $t$ test to assess statistical significance. Bonferroni correction was used for three-way comparisons and $P$ $<0.0167$ was used as a minimum level of significance.

\section{Results}

Alterations in urinary electrolytes, plasma catecholamines, plasma renin activity, and blood pressure with dietary interventions. Normotensive and hypertensive subjects demonstrated comparable alterations in urinary sodium and potassium excretion through the three diet periods (Table I).

During the low sodium diet, plasma renin activity was comparably and significantly increased in both normotensive and hypertensive groups (Table I).

Mean arterial pressure (average of morning measurements taken while subjects were seated on days 4 and 5 of each diet period) was not significantly reduced by a low sodium diet in normotensive or hypertensive subjects (Table I). However, in the subjects in whom paired samples were available (low sodium vs. high sodium/high potassium) the low sodium diet reduced mean arterial pressure in six of eight normotensive subjects (and overall by $3 \pm 2 \mathrm{mmHg}$ ) and eight of eight hypertensive subjects (by $4 \pm 2 \mathrm{mmHg}$ ).

LVDT studies: isoproterenol-mediated vasodilation. A significant decrease in isoproterenol-mediated vasodilation was demonstrated in hypertensive subjects fed a high sodium diet irrespective of potassium intake. While being fed a high sodium/low potassium diet, maximal isoproterenol-mediated vasodilation was significantly reduced in hypertensive subjects, whether expressed as a percentage of baseline distension (normotensives, 93 $\pm 6 \%$; hypertensives, $49 \pm 6 \%, P<0.01$ ) (Fig. $2 a$ ) or as a percentage of maximal nitroglycerin-mediated vasodilation (normotensives, $94 \pm 6 \%$; hypertensives, $55 \pm 5 \%, P$ $<0.01$ ) (Fig. 2 b). In contrast, no statistically significant alterations in $\mathrm{ED}_{50}$ for isoproterenol were noted between normotensive and hypertensive subjects (Table II).

A decrease in maximal isoproterenol-mediated venodilation was also seen in hypertensive subjects fed a high sodium/ high potassium diet (normotensives, $84 \pm 5 \%$; hypertensives, $54 \pm 5 \%, P<0.01$ as a percentage of baseline distension; and normotensives, $88 \pm 3 \%$; hypertensives, $58 \pm 5 \%, P<0.01$ as a percentage of maximal nitroglycerin-induced dilation).

The defect in isoproterenol-mediated response was corrected when hypertensive subjects were fed a 10 meq sodium/ 100 meq potassium diet. During the low sodium diet maximal isoproterenol-mediated vasodilation was significantly increased in hypertensive subjects $(76 \pm 5 \%$ of baseline, $83 \pm 5 \%$ of maximal nitroglycerin-mediated distension, both at $P<0.01$ as compared with the response in hypertensives fed a high sodium/100 meq potassiüm diet) to a level not different from that of normotensive subjects $(87 \pm 8 \%$ of baseline distension, $80 \pm 7 \%$ of maximal nitroglycerin-mediated distension) (Fig. 2). The alterations in maximal isoproterenol-mediated vasodilation were not accompanied by any statistically significant changes in the $\mathrm{ED}_{50}$ of isoproterenol (Table II).

We previously reported that lymphocyte beta-adrenergic responsiveness (as assessed by isoproterenol-stimulated adenylyl cyclase activity) was correlated with plasma renin activity

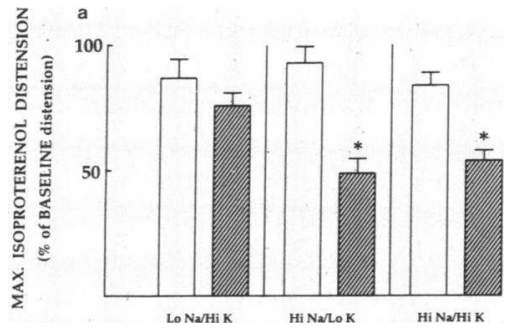

Figure 2. Vascular betaadrenergic responsiveness in normotensive (ㅁ) and hypertensive (ם) subjects. $a$, Maximal isoproterenol-mediated vasodilation was determined by nonlinear curve-fitting analysis, and expressed as the increase in venous distension above the level seen after preconstriction with phenylephrine (at approximately the $\mathrm{ED}_{80}$ dose) relative to the extent of baseline distension. Data represent the arithmetic mean \pm SEM. $b$, Maximal isoproterenol-mediated vasodilation determined as above, but expressed relative to the extent of maximal nitroglycerin-mediated distension. Data represent the arithmetic mean \pm SEM. ${ }^{*} P<0.01$ vs. normotensive controls and hypertensives fed a low sodium chloride diet. 
Table II. Effect of Varying Sodium and Potassium Intake on Venous Responsiveness

\begin{tabular}{|c|c|c|c|c|c|c|}
\hline & \multicolumn{3}{|c|}{ Normotensive } & \multicolumn{3}{|c|}{ Hypertensive } \\
\hline & Low Na/high $\mathrm{K}$ & High Na/low K & High Na/high $\mathrm{K}$ & Low Na/high $\mathrm{K}$ & High $\mathrm{Na} /$ low $\mathrm{K}$ & High Na/high $\mathrm{K}$ \\
\hline & 6.8 & 8.4 & 13.1 & 15.8 & 10.0 & 7.8 \\
\hline \multirow{2}{*}{$\mathrm{ED}_{50}$ isoproterenol $(\mathrm{ng} / \mathrm{min})$} & $(+5.6 /-3.1)$ & $(+5.2 /-3.3)$ & $(+4.0 /-3.1)$ & $(+13.1 /-7.2)$ & $(+4.2 /-3.0)$ & $(+3.7 /-2.5)$ \\
\hline & 240 & 257 & 236 & 318 & 760 & 318 \\
\hline \multirow[t]{2}{*}{$\mathrm{ED}_{s 0}$ phenylephrine (ng/min) } & $(+163 /-95)$ & $(+95 /-69)$ & $(+115 /-77)$ & $(+199 /-122)$ & $(+264 /-196)$ & $(+261 /-143)$ \\
\hline & 933 & 803 & 1064 & 1028 & 1483 & 907 \\
\hline $\mathrm{ED}_{80}$ phenylephrine ( $\left.\mathrm{ng} / \mathrm{min}\right)$ & $(+533 /-399)$ & $(+363 /-250)$ & $(+689 /-418)$ & $(+358 /-265)$ & $(+397 /-313)$ & $(+326 /-240)$ \\
\hline Maximal phenylephrine constriction (\%) & $72 \pm 4$ & $77 \pm 5$ & $78 \pm 7$ & $83 \pm 6$ & $81 \pm 5$ & $81 \pm 3$ \\
\hline Maximal nitroglycerin dilation (\%) & $97 \pm 8$ & $99 \pm 4$ & $102 \pm 7$ & $93 \pm 4$ & $86 \pm 7$ & $93 \pm 4$ \\
\hline Submaximal nitroglycerin dilation (\%) & $85 \pm 9$ & $94 \pm 4$ & $91 \pm 6$ & $91 \pm 5$ & $85 \pm 7$ & $76 \pm 7$ \\
\hline
\end{tabular}

Data are expressed as means \pm SEM. For $\mathrm{ED}_{50}$ values data are expressed as the geometric means and errors. Log transformations of individual $\mathrm{ED}_{50}$ values were performed, and means and standard errors were determined and expressed as antilogs. For example, $\log \mathrm{ED}_{50}=3 \pm 0.1$

$(\log \mathrm{ng} / \mathrm{min})$ would be expressed as $1,000(+260 /-206) \mathrm{ng} / \mathrm{min}(18,19)$.

in hypertensive but not normotensive subjects (1). In the current studies venous beta-adrenergic responsiveness (as assessed by maximal isoproterenol-stimulated vasodilation, percent of baseline distension) was significantly correlated with plasma renin activity in hypertensive subjects $(r=0.61, P<0.001, n$ $=26)$, but not in normotensive controls $(r=-0.21, P=0.30$, $n=27$ ) (data not shown).

LVDT studies: nitroglycerin-mediated vasodilation. In contrast to the decrease in isoproterenol-mediated vasodilation seen in hypertensive subjects fed a high salt diet, there were no significant differences in either maximal $(100 \mathrm{ng} / \mathrm{min})$ or submaximal $(10 \mathrm{ng} / \mathrm{min})$ nitroglycerin-mediated vasodilation (Table II) between hypertensive and normotensive subjects or with alterations in dietary sodium/potassium intake.

LVDT studies: phenylephrine-mediated vasoconstriction. Phenylephrine-mediated venoconstriction did not significantly differ between normotensive and hypertensive subjects, or between varying dietary sodium/potassium intake. Specifically, no statistically significant differences in either the $\mathrm{ED}_{50}$ for phenylephrine-mediated venoconstriction or in the maximal extent of constriction were apparent (Table II). Furthermore, the concentration of phenylephrine used to preconstrict vessels before the assessment of isoproterenol-mediated vasodilation (approximately the $\mathrm{ED}_{80}$ dose for phenylephrine) was also not significantly different either between groups or with alterations in dietary salt intake (Table II).

Correlation between maximal isoproterenol-mediated vasodilation, lymphocyte beta adrenoceptor density, and mean arterial pressure. A highly significant (although not highly predictive) linear correlation between lymphocyte beta adrenoceptor density and maximal isoproterenol-mediated vasodilation regression was noted $(r=0.44, P<0.001)$, including all subjects and all dietary sodium/potassium periods. ${ }^{2}$ In nor-

2. It should be noted that, especially at higher percentages of isoproterenol-mediated vasodilation, the relationship between receptor density and maximal beta-adrenergic vasodilation would not be expected to be linear (since the assessment of isoproterenol-mediated vasodilation by LVDT is essentially limited to a maximum of $\sim 100 \%$ of baseline distension). Therefore, the relationship would be predicted to be better described by a more complex polynomial equation. By fitting the data to a third degree polynomial equation, a higher correlation coefficient was obtained $(r=0.60 ; P<0.0001)$. motensive subjects this correlation was still statistically significant $(r=0.53, P<0.005)$; however, lymphocyte beta adrenoceptor density and vascular beta adrenoceptor response were not correlated in hypertensive subjects $(r=0.06, P=0.77)$ (Fig. 3). Consistent with our previous studies $(4,5)$, lymphocyte beta adrenoceptor density did not differ between normotensive and hypertensive subjects during any of the dietary periods, or change significantly with alterations in dietary sodium and potassium intake (Table III).
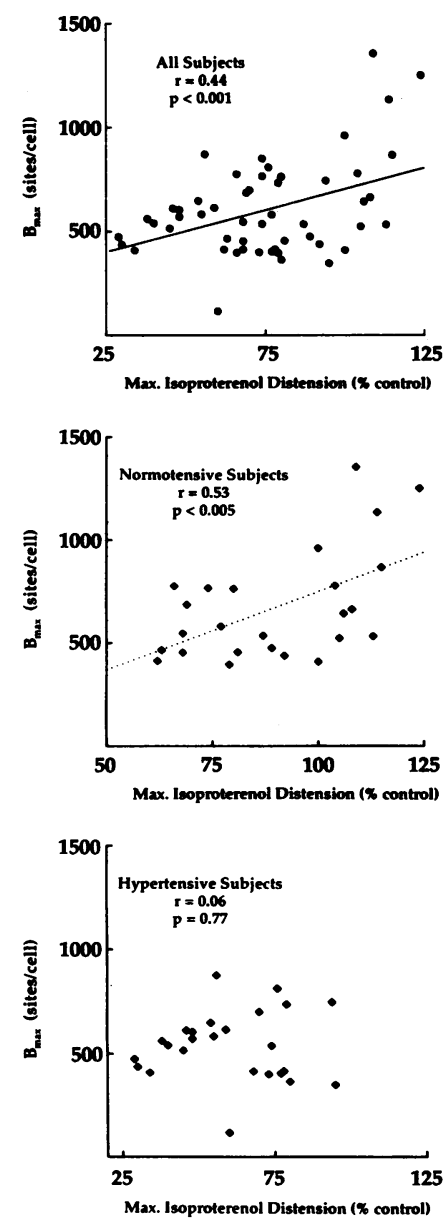

Figure 3. Correlation between lymphocyte beta adrenoceptor density $\left(B_{\max }\right)$ and maximal isoproterenol-mediated venodilation (expressed relative to baseline distension) for all subjects (top), normotensive subjects (middle), and hypertensive subjects (bottom). 
Table III. Alterations in Lymphocyte Beta Adrenoceptor Density with Varying Sodium and Potassium Intake

\begin{tabular}{llr}
\hline & \multicolumn{2}{c}{ Lymphocyte beta adrenoceptor density } \\
& \multicolumn{2}{c}{ (sites/cell) } \\
\cline { 2 - 3 } & Normotensive & Hypertensive \\
\hline Low Na/high K & $646 \pm 78$ & $520 \pm 87$ \\
High Na/low K & $717 \pm 109$ & $542 \pm 44$ \\
High Na/high K & $637 \pm 51$ & $538 \pm 34$ \\
\hline
\end{tabular}

There were no significant differences in beta adrenoceptor density between hypertensive and normotensive subjects, or between varying sodium and potassium intake.

Overall, mean arterial pressure had a weak negative correlation with maximal isoproterenol-mediated vasodilation $(r$ $=-0.42, P<0.005)$ and lymphocyte beta ${ }_{2}$ adrenoceptor density $(r=-0.34, P<0.0167)$ (data not shown).

\section{Discussion}

The present studies indicate that in borderline hypertensive subjects fed a high sodium chloride diet, venous beta-adrenergic responsiveness is reduced. This appears to be a specific defect, in that nitroglycerin-mediated vasodilation was not different in borderline hypertensive subjects and normotensive controls. In addition, hypertensive subjects fed a low sodium diet show a normalization of venous beta-adrenergic responsiveness to a level no different from that seen in normotensive controls. The specificity of this defect in venous beta-adrenergic response and its reversibility suggest that it represents a functional abnormality and is not due to a fixed structural alteration in the vessel wall.

The reduction in isoproterenol-mediated venodilation in hypertensive subjects fed a high sodium chloride diet parallels the previously documented alterations in lymphocyte betaadrenergic responsiveness $(4,5)$ and may be analogous to the defect in venodilation described in the elderly (11). Together these data are consistent with a selective defect in the venous beta adrenoceptor complex which is common to the lymphocyte beta adrenoceptor complex. However, a more generalized defect in venodilator response to those hormone receptor systems that act through elevations of cAMP could certainly not be excluded by the current studies alone. To do this would require a more detailed characterization of vascular response to other agonists that mediate vasodilation through adenylyl cyclase activation, such as $\mathrm{PGE}_{1}$.

The mechanism of the increase in beta-adrenergic responsiveness during a low sodium diet remains unclear. In vitro, increasing sodium concentration reduces beta adrenoceptor response $(20,21)$. Further, intracellular sodium content may be higher in hypertensives (22), and is reduced with dietary sodium restriction (23). Thus, changes in intracellular sodium could regulate both lymphocyte and venous beta-adrenergic response. However, in the previously reported studies of lymphocyte beta-adrenergic responsiveness, assays were performed in broken cell preparations in the presence of isotonic saline buffers $(4,5)$. Thus, if a change in intracellular sodium was responsible for a common alteration in both venous and lymphocyte beta-adrenergic responses, those effects must be persistent even after cell lysis and with the determination of adenylyl cyclase activity at sodium concentrations well above intracellular levels.

No alterations in phenylephrine (alpha adrenergic)-mediated vasoconstriction were apparent in hypertensive subjects. This is consistent with several recent studies which found no evidence of a selective increase in vascular alpha adrenoceptor-mediated vasoconstriction in essential hypertensive subjects $(24,25)$, including a recent report using LVDT techniques (26). However, as stressed by Alradi and Carruthers, the variability of $\mathrm{ED}_{50}$ values determined by LVDT precludes a definitive conclusion regarding differences in phenylephrinemediated vasoconstriction in trials with small numbers of subjects such as ours. ${ }^{3}$

These studies also illustrate the limitations as well as the

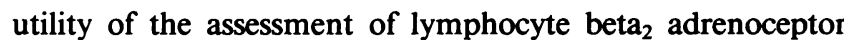
density when used as an index of human vascular beta ${ }_{2}$-adrenergic responsiveness. Lymphocyte beta adrenoceptor density was significantly correlated with (although not highly predictive of) venous beta $a_{2}$-adrenergic responsiveness. Also, in the subset of normotensive subjects there was a highly significant correlation between lymphocyte beta ${ }_{2}$ adrenoceptor density and vascular response. Together with the studies of Michel et al. $(6,7)$ this would suggest that in normal subjects lymphocyte beta $_{2}$ adrenoceptor density may be an index of both cardiac and vascular beta ${ }_{2}$-adrenergic responsiveness. In the subset of hypertensive subjects, however, lymphocyte beta ${ }_{2}$ adrenoceptor density was not correlated with vascular response. Thus, lymphocyte beta $_{2}$ adrenoceptor density may not be a valid index of the cardiovascular beta ${ }_{2}$-adrenergic responsiveness in hypertensives. Further, when fed a high sodium chloride diet the reduction in beta-adrenergic vascular response in hypertensive subjects did not parallel a reduction in lymphocyte beta adrenoceptor density. In previous studies we reported that the reduction in beta-adrenergic lymphocyte responsiveness (assessed by adenylyl cyclase activity) did not parallel a reduction in lymphocyte beta adrenoceptor density $(4,5)$. Together these data tend to support our suggestion that in the hypertensive state the defect in the lymphocyte beta ${ }_{2}$ adrenoceptor complex occurs at a point distal to the recognition unit of the receptor (i.e., the defect is not due to downregulation of receptor density).

The mechanism by which reduced venous beta ${ }_{2}$-adrenergic responsiveness might be associated with the pathogenesis and/ or maintenance of hypertension remains unclear. However, if the reduction in venous response to beta ${ }_{2}$-adrenergic stimulation in hypertensives fed a high salt diet paralleled a similar arterial defect, one might hypothesize that reduced arterial beta $_{2}$-adrenergic response could be important in maintaining increased peripheral resistance. Additionally, and more directly, several groups have documented a reduction in venous compliance in hypertensive subjects $(27,28)$. They have suggested that reduced venous compliance might be an important step in the pathogenesis and/or maintenance of the hypertensive state. A defect in beta adrenergic-mediated venous vasodilator function (in the setting of increased sympathoadrenal activation) could be a potential mechanism for this reduction

3. Power calculations based on the observed variability of $\mathrm{ED}_{50}$ values for phenylephrine and isoproterenol suggested that with the sample size of the present study (8-11/group) the smallest detectable difference in $\mathrm{ED}_{50}$ between groups (alpha $=0.01 ; 1$-beta $=0.08$ ) would have been a three- to fourfold alteration. 
in compliance. Especially when aggravated by a high sodium intake, a reduction in venous compliance would tend to increase preload and hence stroke volume and consequently blood pressure. It is interesting that this pattern of changes may parallel those seen in early hypertension (as reviewed in reference 29). Therefore, in this schema defective venous beta adrenoceptor vascular response could potentially be important in maintaining if not initiating the hypertensive state in borderline subjects.

In summary, the current study demonstrates that betaadrenergic responsiveness is selectively reduced in the peripheral veins of borderline hypertensive subjects and is corrected by a low sodium chloride diet. These findings parallel the previously reported alterations in lymphocyte beta ${ }_{2}$-adrenergic responsiveness in hypertension. The demonstration of a reduction in lymphocyte and now in venous beta ${ }_{2}$-adrenergic responsiveness suggests the possibility of a generalized defect of the beta ${ }_{2}$-adrenergic receptor complex in human hypertension. These studies also suggest an important role of dietary sodium chloride in regulating this defect.

\section{Acknowledgments}

The author gratefully acknowledges the advice and help of Dr. George Carruthers in the development of the LVDT methods described in these studies; the assistance of Dr. William Lawton in analysis of urinary electrolytes and plasma renin activity; the assistance of the Clinical Research Center nursing staff directed by Kay Schabold, B.S.N., and the dieticians of the Clinical Research Center, Phyllis Stumbo, Ph.D., R.D.L.D. and Catherine Chenard, B.S., R.D.L.D.; Dr. Allyn Mark and Dr. Melvin Marcus for their constructive comments in reviewing these studies; and Mrs. Theresa Mayhew for preparing the manuscript.

These studies were supported by Public Health Service grants HL-32501 and HL-32296, and Clinical Research Center Program grant RR-059. Dr. Feldman was a Burroughs-Wellcome Scholar in Clinical Pharmacology.

\section{References}

1. Feldman, R. D. 1987. Beta-adrenergic receptor alterations in hypertension-physiological and molecular correlates. Can. J. Physiol. Pharmacol. 65:1666-1672.

2. Borkowski, K. R. 1988. Pre- and postjunctional beta-adrenoceptors and hypertension. J. Auton. Pharmacol. 8:153-171.

3. Jennings, G., A. Bobik, M. Esler, and P. Korner. 1981. Contribution of cardiovascular reflexes to differences in beta-adrenoceptormediated responses in essential hypertension. Clin. Sci. 61:177s-180s.

4. Feldman, R. D., L. E. Limbird, J. Nadeau, D. Robertson, and A. J. J. Wood. 1984. Leukocyte beta-receptor alterations in hypertensive subjects. J. Clin. Invest. 73:648-653.

5. Feldman, R. D., W. J. Lawton, and W. L. McArdle. 1987. Low sodium diet corrects the defect in lymphocyte beta-adrenergic responsiveness in hypertensive subjects. J. Clin. Invest. 79:290-294.

6. Michel, M. C., J. J. Beckeringh, K. Ikezono, R. Kretsch, and O. E. Brodde. 1986. Lymphocyte beta ${ }_{2}$-adrenoceptor changes in the human heart. J. Hypertens. 4(Suppl 6):S215-S218.

7. Michel, M. C., A. Pingsmann, J. J. Beckeringh, H. R. Zerkowski, N. Doetsch, and O. E. Brodde. 1988. Selective regulation of beta ${ }_{1}$ - and beta ${ }_{2}$-adrenoceptors in the human heart by chronic beta-adrenoceptor antagonist treatment. Br. J. Pharmacol. 94:685-692.

8. Aellig, W. H. 1981. A new technique for recording compliance of human hand veins. Br. J. Clin. Pharmacol. 11:237-243.

9. Aellig, W. H. 1984. Investigation of the venoconstrictor effect of $8^{\prime}$ hydroxydihydroergotamine, the main metabolite of dihydroergotamine, in man. Eur. J. Clin. Pharmacol. 26:239-242.

10. Alradi, A. O., and S. G. Carruthers. 1985. Evaluation and application of the linear variable differential transformer technique for the assessment of human dorsal hand vein alpha-receptor activity. Clin. Pharmacol. Ther. 38:495-502.

11. Pan, H. Y.-M., B. B. Hoffman, A. Pershe, and T. F. Blaschke. 1986. Decline in beta adrenergic receptor-mediated vascular relaxation with aging in man. J. Pharmacol. Exp. Ther. 239:802-807.

12. Martin, S. A., S. Alexieva, and S. G. Carruthers. 1986. The influence of age on dorsal hand vein responsiveness to norepinephrine. Clin. Pharmacol. Ther. 40:257-260.

13. Eichler, H. C., A. Hiremath, D. Katzir, T. F. Blaschke, and B. Hoffman. 1987. Absence of age related changes in venous responsiveness to nitroglycerin in vivo in humans. Clin. Pharmacol. Ther. 42:521-524.

14. Haber, E., T. Loerner, L. Page, B. Klimar, and A. Purnode. 1969. Application of a radioimmunoassay for angiotensin I to the physiologic measurement of plasma renin activity in normal human subjects. J. Clin. Endocrinol. 29:1349-1355.

15. Boyum, A. 1968. Isolation of mononuclear cells and granulocytes from human blood. Scand. J. Clin. Lab. Invest. 2(Suppl 97):7789.

16. Feldman, R. D. 1989. Beta-adrenergic desentization reduces the sensitivity of adenylate cyclase for magnesium in permeabilized lymphocytes. Mol. Pharmacol. 35:304-310.

17. Thede-Reynolds, K. R., J. H. Motulsky, and R. D. Feldman. 1986. Temperature-dependent binding of hydrophilic beta-adrenergic receptor ligands to intact human lymphocytes. Life Sci. 39:1325-1334.

18. DeLean, A., A. A. Hancock, and R. J. Lefkowitz. 1982. Validation and statistical analysis of a computer modeling method for quantitative analysis of radioligand binding data for mixtures of pharmacological receptor subtypes. Mol. Pharmacol. 21:5-16.

19. Hancock, A. A., E. N. Bush, D. Stanisic, J. J. Kyncl, and C. T. Lin. 1988. Data normalization before statistical analysis: keeping the horse before the cart. Trends Pharmacol. Sci. 9:29-32.

20. Jakobs, K. H., M. Minuth, and K. Aktories. 1984. Sodium regulation of hormone-sensitive denylate cyclase. J. Recept. Res. 4:443-458.

21. Minuth, M., and K. H. Jakobs. 1986. Sodium regulation of agonist and antagonist binding to beta-adrenoceptors in intact and $\mathrm{N}_{\mathrm{s}}$-deficient membranes: Naunyn-Schmiedeberg's Arch. Pharmacol. 333:124-129.

22. Ambrosioni, E., F. V. Costa, C. Borghi, S. Boschi, and A. Mussi. 1986. Cellular and humoral factors in borderline hypertension. J. Cardiovasc. Pharmacol. 8:S15-S22.

23. Ambrosioni, E., F. V. Costa, C. Borghi, L. Montebugnoli, M. F. Giordani, and B. Magnani. 1982. Effects of moderate salt restriction on intralymphocytic sodium and pressor response to stress in borderline hypertension. Hypertension (Dallas). 4:789-794.

24. Egan, B., R. Panis, A. Hinderliter, N. Schork, and S. Julius. 1987. Mechanism of increased alpha adrenergic vasoconstriction in human essential hypertension. J. Clin. Invest. 80:812-817.

25. Jie, K., P. van Brummelen, P. Vermey, P. Timmermans, and P. A. van Zwieten. 1985. Alpha ${ }_{1}$ - and alpha $a_{2}$-adrenoceptor mediated vasoconstriction in the forearm: differences between normotensive and hypertensive subjects. J. Hypertens. 3(Suppl 3):S89-S91.

26. Eichler, H. G., G. A. Ford, T. F. Blaschke, A. Swislocki, and B. B. Hoffman. 1989. Responsiveness of superficial hand veins to phenylephrine in essential hypertension. J. Clin. Invest. 83:108-112.

27. Takeshita, A., and A. L. Mark. 1979. Decreased venous distensibility in borderline hypertension. Hypertension (Dallas). 1:202-206.

28. Safar, M. E., and G. M. London. 1987. Arterial and venous compliance in sustained essential hypertension. Hypertension (Dallas). 100:133-139.

29. Korner, P. I. 1984. The pathogenesis of hypertension: the Baker concerto. Clin. Exp. Hypertens. Part A Theory Pract. A6:565-586. 